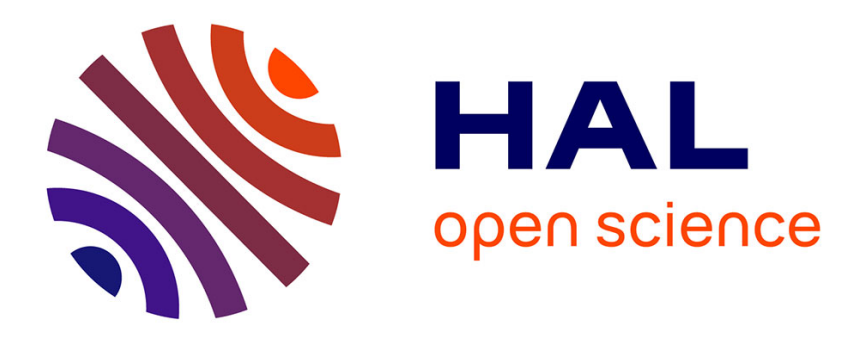

\title{
Efficient modeless laser for a mesospheric sodium laser guide star
}

\author{
J. P. Pique, Sébastien Farinotti
}

\section{To cite this version:}

J. P. Pique, Sébastien Farinotti. Efficient modeless laser for a mesospheric sodium laser guide star. Journal of the Optical Society of America, 2003, 20. (10), pp.2093-2101. 10.1364/JOSAB.20.002093 . hal-01118356

\section{HAL Id: hal-01118356 https://hal.science/hal-01118356}

Submitted on 3 Mar 2015

HAL is a multi-disciplinary open access archive for the deposit and dissemination of scientific research documents, whether they are published or not. The documents may come from teaching and research institutions in France or abroad, or from public or private research centers.
L'archive ouverte pluridisciplinaire HAL, est destinée au dépôt et à la diffusion de documents scientifiques de niveau recherche, publiés ou non, émanant des établissements d'enseignement et de recherche français ou étrangers, des laboratoires publics ou privés. 


\title{
An efficient modeless laser for a mesospheric sodium laser guide star
}

\author{
Jean-Paul Pique and Sébastien Farinotti \\ Laboratoire de Spectrométrie Physique, Université Joseph Fourier, UMR 5588 CNRS- \\ Grenoble I, B.P. 87, 38402 saint Martin d'Hères
}

Within the framework of laser-guide-star and in order to solve the major problem of the saturation of sodium atom, we present an "all-optical" modeless-laser which excites all sodium velocity classes. A theoretical and experimental study of the excitation of the sodium- $\mathrm{D}_{2}$ line is presented in three cases: a single-mode laser of line-width $1 \mathrm{MHz}$, a modeless laser of line-width $4.5 \mathrm{GHz}$ and $3 \mathrm{GHz}$. The best result is obtained when the line-width matches the Doppler-Hyperfine sodium $\mathrm{D}_{2}$-line profile. By comparison with a single-mode laser excitation, we show that our modeless-laser $\mathrm{D}_{2}$-sodium star hence becomes six time brighter.

PACS: 42.55.-f, 42.55.Mv, 42.60.By, 42.60.Fc, 32.00.00, 32.80.-t, 95.75.Qr

\section{Introduction}

It is now internationally accepted that, owing to the poor sky coverage of natural guide stars, the future of adaptive optics in astronomy requires the use of sodium laser guide 
stars $^{1}$. Following real demonstrations (Mauna $\mathrm{Kea}^{2}$, Lawrence Livermore National Laboratory (LLNL) ${ }^{3}$, MMT (Multiple Mirror Telescope) Observatory ${ }^{4}$, Calar Alto Observatory $^{5}$, Lick Observatory ${ }^{6}$, Sac Peak Observatory ${ }^{7}$ ), major new astronomical sites are about to be equipped with lasers. The most advanced project is that of the Keck observatory $^{8}$ where an $18 \mathrm{~W}$ pulsed dye laser of ALVIS (Atomic Vapor Laser Isotope Separation) type is operational. In 2003, one of four Very Large Telescopes (VLT) of ESO (European Southern Observatory) ${ }^{9}$ in Chile will be equipped with a $10 \mathrm{~W}$ cw laser comprising five dye jets pumped by five $10 \mathrm{~W}$ cw green YAG lasers. In 2004 the Gemini North Telescope will be equipped with a $20 \mathrm{~W}$ laser that frequency sums two picosecond YAG lasers (500 ps), pumped by diode lasers ${ }^{10}$. Several new $589 \mathrm{~nm}$ laser sources are under study. AFRL (Air Force Research Laboratory, USA) is developing frequency mixing of two cw YAG lasers in a nonlinear crystal of $\mathrm{LBO}_{3}$ within an optical cavity ${ }^{11}$. LLNL and ESO are developing a cw laser from frequency mixing in a Periodically poled crystal of a Nd:silica fiber laser $(938 \mathrm{~nm})$ and an $\mathrm{Er} / \mathrm{Yb}$ fiber laser $(1583 \mathrm{~nm})^{12}$. Frequency doubling of a $1178 \mathrm{~nm}$ Raman fiber laser is also being considered ${ }^{13}$.

Generally speaking, two types of lasers are possible: continuous and pulsed. In the near future, cw lasers, at the wavelengths of the $\mathrm{D}_{2}$-sodium-line $(\sim 589 \mathrm{~nm})$, will not exceed 10 W. However, pulsed lasers can reach mean powers up to $1000 \mathrm{~W}$ at this wavelength ${ }^{3}$. The major drawback of pulsed lasers is the saturation of the $3 S_{1 / 2} \diamond \quad 3 P_{3 / 2}$ sodium transition. The saturation density peak power of the $\mathrm{D}_{2}$-line is $I_{\text {sat }}=95.4 \mathrm{Wm}^{-2}$. Typically, a single longitudinal mode laser of average power 18 Watts, with repetition rate of $26 \mathrm{kHz}$ and pulse duration of $100 \mathrm{~ns}$, provides a peak power of about $7000 \mathrm{~W}$. For a beam diameter $2 w$ of $30 \mathrm{~cm}$, the power density is $P_{w} \approx 10^{5} \mathrm{Wm}^{-2}$ and the saturation parameter 
is $S=P_{w} / I_{\text {sat }} \approx 1000$. Physically, saturation means that the vapor medium becomes transparent. Under these conditions, it is clear that the returned fluorescence flux is far from being optimized. In spite of the use of phase modulators, this limitation has not so far been solved (we shall see below the limits of this technique). Another strong constraint at astronomical sites is compactness, reliability and therefore simplicity of the laser system.

In this paper, we show experimentally that a modeless laser fulfills the two criteria mentioned above. As will be seen, this is an all-optical laser (with no electronic servocontrol) that is insensitive to vibrations and temperature drift. It is thus reliable and robust. Moreover, the laser line of the modeless laser channel we have developed, which covers all sodium Doppler-hyperfine $\mathrm{D}_{2}$-lines with no frequency gap, enables a pulsed laser with high mean power (up to 100 watts) to be used with a returned fluorescence flux close to that of a cw laser of the same mean power. This latter point is important, since in the near future developments of new cw lasers will not allow powers higher than a few tens of Watts ${ }^{1}$. However, the findings of the above mentioned research clearly show that powers much higher than several tens of watts will be required, especially for observations with visible light. This is even more true for the polychromatic laser guide star project ELP-OA ${ }^{14} 1516$ (Etoile Laser Polychromatique pour Optique Adaptative). the aim of which is to ensure a $100 \%$ sky coverage for near-diffraction-limited observations. This project requires two $25 \mathrm{~W}$ lasers $(589 \mathrm{~nm}$ and $569 \mathrm{~nm}$ ). We are working within the framework of ELP-OA project, but the results we have obtained are also useful for monochromatic laser guide star projects. 


\section{Saturation of the sodium $\mathbf{D}_{2}$-transition}

The effects of saturation of sodium atom $\mathrm{D}_{2}$-transition, induced by pulsed lasers, were studied by Megie $^{17}$ in 1977 during LIDAR experiments. They were then analyzed in detail $^{18} 19$. In 1994 Morris $^{20}$ proposed to use a series of phase modulators to widen the spectral bandwidth of a single-longitudinal-mode laser by creation of spectral side-bands. This solution was adopted in the Keck observatory laser system. Unfortunately, the technique is severely limited. The modulation frequency is limited on the one hand by the Doppler width $\Delta v_{D} \approx 1 G H z$, and on the other hand by the inverse of the laser pulse width $\Delta v_{L}=1 / \tau_{L} \approx 25 \mathrm{MHz}$. First, side-modes must not exceed the Doppler width and second, in order to create intense side-modes, phases must oscillate a sufficient number of times during the pulse duration ${ }^{16}$. In practice, modulation frequencies must be chosen in the range 100-300 MHz. The best result was obtained with two successive modulators with $\mathrm{RF}$ frequencies of $180 \mathrm{MHz}$ and $325 \mathrm{MHz}^{2122}{ }^{23}$. This configuration gives less than 10 side-modes inside the spectrum of the $\mathrm{D}_{2}$-line. It was verified that the gain achieved by using double phase modulation does not exceed a factor of $1.8^{21}$. In the framework of monochromatic laser guide star projects, we note that an equivalent gain is easily obtained with a multimode laser. Moreover, two multimode lasers cannot be used to create the radiative cascade of the ELP-OA project, since the velocity classes of the sodium atoms prepared by the first laser modes cannot strictly coincide with those seen by the second laser mode.

We restrict the presentation of this paper to the case of the production of a monochromatic sodium star $\left(\mathrm{D}_{2}\right.$-transition from state number $1: 3 S_{1 / 2}$ towards state number 2: $\left.3 P_{3 / 2}\right)$. To evaluate the gain achieved by a modeless laser we used a rate- 
equation model, which is valid ${ }^{17}$ in the case of the $\mathrm{D}_{2}$-transition, provided that the width of the laser pulse is larger than the radiative lifetime $\tau_{21}$ (16 ns for the $3 P_{3 / 2}$ state of the sodium atom). Calculations performed within the more rigorous density-matrix framework $^{202425}$ do not show any significant improvement over the rate-equation model as long as the above assumption is valid. Coherent effects are not included in the rateequation models, but are completely negligible in our case. Indeed, the lasers used have pulse areas that are much smaller than $\pi$. Furthermore, in contrast to density-matrix models, the spatial beam profile can be taken into account in rate-equation models. The resulting effect is far stronger than those neglected. We thus used a generalized model that includes the effects of arbitrary beam cross sections and inhomogeneous broadening. The time evolution of population $N_{2}$ of the excited level $2\left(3 P_{3 / 2}\right)$ is the sum of absorption, spontaneous emission and stimulated emission processes

$$
\begin{aligned}
\frac{\partial N_{2}(t, \mathbf{r}, v)}{\partial t} & =N_{1}(t, \mathbf{r}, v) \int_{-\infty}^{+\infty} \sigma\left(v^{\prime}-v\right) \Phi\left(t, \mathbf{r}, v^{\prime}\right) d v^{\prime}-\frac{N_{2}(t, \mathbf{r}, v)}{\tau_{21}} \\
& -N_{2}(t, \mathbf{r}, v) \frac{g_{1}}{g_{2}} \int_{-\infty}^{+\infty} \sigma\left(v^{\prime}-v\right) \Phi\left(t, \mathbf{r}, v^{\prime}\right) d v^{\prime}
\end{aligned}
$$

Where:

$t=\operatorname{time}(s)$

$\mathbf{r}=$ vector of the radial position in the laser beam $(\mathrm{m})$

$v=$ frequency Doppler shift $(\mathrm{Hz})$

$g_{1}, g_{2}$ degeneracy of the $3 S_{1 / 2}$ and $3 P_{3 / 2}$ states respectively

$\tau_{21}=$ radiative lifetime of the $3 P_{3 / 2}$ level $\left(16.10^{-9} \mathrm{~s}\right)$

$\Phi=$ laser photon flux density per unit area, unit time and unit frequency $\left(m^{-2} \mathrm{~s}^{-1} \mathrm{~Hz}^{-1}\right)$ 
$\sigma=$ homogeneous absorption cross section $\left(\mathrm{m}^{2}\right)$

$N_{l}=$ population of the fundamental level 1

A commonly used approximation consists in assuming $\Phi$ to be separable ${ }^{18}$. Consequently, it is expressed as the product of the laser temporal pulse shape $\varphi(t)$ (number of photons per second), the spatial distribution of the photons per unit area $D(\mathbf{r})$ $\left(\mathrm{m}^{-2}\right)$ and the line profile $g(v)\left(\mathrm{Hz}^{-1}\right)$

$\Phi(t, \mathbf{r}, v)=\varphi(t) D(\mathbf{r}) g(v)$

$D$ and $g$ are normalized to 1 and $\int_{\text {pulse }} \varphi(t) d t=N_{L}$, where $N_{L}$ is the total number of photons per laser pulse. It follows that

$$
\int_{-\infty}^{+\infty} \sigma\left(v^{\prime}-v \Phi t(\mathbf{r}, v, d \eta)=\varphi t D(\mathbf{r}) \sigma_{d f f}\right) v
$$

Where the effective cross section $\sigma_{e f f}$ is the convolution product of the homogeneous line of the sodium atom and the laser line shape

$$
\sigma_{e f f}(v)=\int_{-\infty}^{+\infty} \sigma\left(v^{\prime}-v g k d v\right)
$$

$\sigma_{\text {eff }}$ describes the absorption cross section of a given velocity class of atoms interacting with the laser field. The homogeneous absorption line has a Lorentzian profile

$$
\sigma(v)=\frac{\sigma_{0}(\Delta v / 2)^{2}}{\left(v_{0}-v\right)^{2}+(\Delta v / 2)^{2}}
$$

$\Delta v$ is the homogeneous line-width of the transition and $v_{0}$ the frequency line center. Saturation power and cross section are connected by the following relation 


$$
I_{s a t}=\frac{h v}{\sigma_{0} \tau_{21}}
$$

At the line center, the saturation power is given by ${ }^{20}$

$$
I_{s a t}=\frac{\pi h c}{2 \lambda^{3} \tau_{21}}
$$

At the line center, the cross section and the saturation power are respectively equal to $\sigma_{0} \approx 2.2 \times 10^{-9} \mathrm{~cm}^{2}$ and $I_{\text {sat }} \approx 9.54 \mathrm{~mW} \cdot \mathrm{cm}^{-2}$. The time and spatial power is written as

$$
I(t, \mathbf{r})=h v \int_{-\infty}^{+\infty} \Phi(t, \mathbf{r}, v) d v=h v \varphi(t) D(\mathbf{r})
$$

We define the saturation parameter as

$$
S(t, \mathbf{r}, v)=\frac{I(t, \mathbf{r})}{I_{s a t}(v)}=\varphi(t) D(\mathbf{r}) \sigma_{e f f}(v) \tau_{21}
$$

$S$ is a dimensionless parameter that depends on the pulse shape, the laser spectral line shape and the position of atoms across the laser beam. Low values of $S$ optimize the returned fluorescence flux. Equation (1) is then expressed as a function of the saturation parameter $S$

$$
\frac{\partial N_{2}(t, \mathbf{r}, v)}{\partial t}=\frac{S(t, \mathbf{r}, v)}{\tau_{21}}\left[N(v)-N_{2}(t, \mathbf{r}, v)\left(1+\frac{g_{1}}{g_{2}}\right)\right]-\frac{1}{\tau_{21}} N_{2}(t, \mathbf{r}, v)
$$

where

$$
\int_{-\infty}^{+\infty} N(v) d v=N_{0}
$$

$N(v)$ is the density of sodium atoms per unit of Doppler frequency and $N_{O}$ the total density of sodium atoms $\left(\mathrm{m}^{-3}\right)$. The Doppler effect is included in the factor $N . S$ contains the effect of saturation, which is an intrinsic property of the sodium atom induced by the spatial and temporal characteristics of the laser beam. A value of $S$ of the order of unity is 
acceptable. Moreover, with large $S$ values the returned fluorescence flux can be catastrophic. Neglecting non-radiative processes, the intensity of the $\mathrm{D}_{2}$ artificial star is directly proportional to the total population of the excited level

$$
N_{2}^{T}=\int_{-\infty}^{+\infty} d v \int_{-\infty}^{+\infty} d^{2} \mathbf{r} \int_{\text {pulse }} N_{2}(t, \mathbf{r}, v) d t
$$

Numerical solution of equation (10) and calculation of the integral (12) give $N_{2}^{T}$ for any spatial and temporal shape. The shape of $N_{2}^{T}$ versus laser power is very sensitive to the beam cross section $D$. We assume a Gaussian beam cross section. In a strongly saturated situation, the diameter of the fluorescence spot can be much larger than the laser diameter. This causes degradation of the resolution. By contrast, as we shall be comparing different laser spectral line profiles, the pulse shape is less critical. For simplicity, we assume a rectangular pulse shape of temporal width $\tau_{L}$. This assumption leads to a simple solution of the differential equation (10)

$$
\begin{array}{ll}
N_{2}(t, \mathbf{r}, v)=N_{s t a}(\mathbf{r}, v) \cdot\left\{1-\exp \left[-S^{\prime} \mathbf{r}\left(v, \frac{t}{\tau_{21}}\right]\right\}\right. & \quad \notin t<\tau_{L} \\
N_{2}(t, \mathbf{r}, v)=N_{s t a}(\mathbf{r}, v) \cdot \exp \left(-\frac{t-\tau_{L}}{\tau_{21}}\right) & t>\tau_{L}
\end{array}
$$

The stationary solution is

$$
N_{s t a}(\mathbf{r}, v)=N(v) \frac{S(\mathbf{r}, v)}{S^{\prime} \mathbf{r}(v,}
$$

where

$$
\begin{aligned}
& S(\mathbf{r}, v)=\tau_{21} \sigma_{e f f}(v) D(\mathbf{r}) \frac{N_{L}}{\tau_{L}} \\
& S^{\prime} \mathbf{r}\left(v, \neq+\quad\left(+\frac{g_{1}}{g_{2}} S\right) \mathbf{r}(v,\right.
\end{aligned}
$$


Calculations were carried out with a Gaussian inhomogeneous line shape of width $3 \mathrm{Ghz}$ (which is close to the total Doppler/hyperfine line-width of the $\mathrm{D}_{2}$ sodium transition), a laser line-width $\tau_{L}=40 \mathrm{~ns}$ and $80 \mathrm{~ns}$, a laser repetition rate of $f_{L}=15 \mathrm{kHz}$ and $30 \mathrm{kHz}$, a beam waist of $w=0.2 m$ (half diameter at $1 / \mathrm{e}^{2}$ ). Although it has been shown ${ }^{17} 26$ that the density of sodium varies strongly inside the mesospheric layer, for simplicity we take a homogeneous density of $N_{0}=5.10^{9} \mathrm{~m}^{-3}$. The returned flux from the mesosphere is given by $^{17}$

$$
\Phi_{D_{2}}=f_{L} \frac{A \Delta z}{4 \pi z^{2}} \frac{N_{2}^{T}}{\tau_{21}}
$$

where $A$ is the receiver area (equal to $1 \mathrm{~m}^{2}$ in the following calculations), $\Delta z$ the thickness of the sodium layer $(\sim 10 \mathrm{~km})$ and $z$ the altitude of the sodium layer $(\sim 90 \mathrm{~km})$. Atmospheric turbulence and transmission are not taken into consideration because the corresponding multiplicative factor $(<1)$ depends on the geographical site. Fig. 1 displays the return flux for three types of laser, versus the average laser power $P_{L}^{a v}=f_{L} h v \int_{p u l s e} \varphi(t) d t$ : i) a single longitudinal mode laser of spectral width $1 \mathrm{MHz}$ centered at the maximum of the inhomogeneous line, ii) the same laser followed by a double phase modulation of $180 \mathrm{MHz}$ and $300 \mathrm{MHz}$, which gives about 5 side-band modes inside the inhomogeneous line, iii) a modeless laser of spectral width $3 \mathrm{GHz}$, i.e., one whose spectral line covers the Doppler-Hyperfine inhomogeneous sodium line with no gap. Our result in cases i) and ii) is very similar to the result obtained by Morris ${ }^{20}$. For example, the star on Fig. 1 corresponds to a pulse intensity of $4 \mu \mathrm{J} / \mathrm{cm}^{2}$ and a backscatter emission per pulse $B_{s} \approx 0.08$ photons / srad / atom in Morris paper ${ }^{20}$ (Fig. 5 of ref. 20, 
unmodulated). Comparison with our units yields a corresponding return flux $\Phi_{D_{2}}$ very close to our result (see Fig. 1)

$\Phi_{D_{2}}=B_{s} \times 4 \pi \times \frac{A}{4 \pi z^{2}} \times N_{0} \pi w^{2} \Delta z \times f_{L} \approx 0.9 \times 10^{6}$ photons $/ \mathrm{s} / \mathrm{m}^{2}$.

The right-hand scale of Fig. 1 shows the gain achieved in the various cases studied, compared with a single-mode excitation of $1 \mathrm{MHz}$ and an average laser power of $25 \mathrm{~W}$. The result for the phase modulated laser is in good agreement with laboratory experiments ${ }^{27}$ and the Pierrelatte experiment ${ }^{15}$. It is clear that a modeless laser is a good solution up to relatively large laser powers. The corresponding return flux with a $30 \mathrm{kHz}-$ $80 \mathrm{~ns}$ laser is less than half of that expected from a cw laser of the same power. It is also clear from our present results that a larger mesospheric beam diameter would give better results. We conclude that a return flux specification of $3 \times 10^{6}$ photons $/ \mathrm{s}^{2} \mathrm{~m}^{2}$ (Keck specification) is easily obtained with a modeless laser.

We thus plan to study and develop a modeless laser that can excite all mesospheric sodium atom velocity classes. The effect of saturation should thus be considerably reduced. For the ELP-OA project ${ }^{16}$ two modeless lasers will be required.

\section{Sodium modeless laser (experimental set-up)}

Several types of modeless laser have been considered in the literature. A multi-pass cavity configuration has been used to amplify the ASE of a dye cell pumped by a $10 \mathrm{~Hz}$ frequency doubled YAG laser ${ }^{28}$. Unfortunately, this simple system does not work for line-widths below $30 \mathrm{GHz}$. This limitation is mainly due to the losses introduced into the cavity by the selective elements. Absence of mode has been demonstrated ${ }^{29}{ }^{30}$ in the cavity of a ring laser pumped by an argon laser with an acousto-optic modulator. Although this result was very promising, the limitations were due principally to the 
strong pump power (ca. 8 Watts) as well as to the fact that the extraction of the output beam was done at the zeroth order of the modulator. Another solution consists of a laser with a very long cavity, so that the free spectral range $i s l_{c}$ becomes smaller than the homogeneous width of the sodium $\mathrm{D}_{2}$-transition $(\sim 10 \mathrm{MHz})$. It has been demonstrated ${ }^{31}$ that a dye laser with an $i s l_{c}$ of $8.8 \mathrm{MHz}$ (cavity length $17 \mathrm{~m}$ ) could work, but was very difficult to align.

We have therefore chosen to study a modeless laser pumped by a cw frequency doubled YAG laser of low power ( $<2$ Watts, Coherent/VERDI). Our modeless laser contains an intra-cavity preamplifier pumped by a pulsed Q-switched high repetition rate YAG laser (Fig. 2). The pre-amplification system will not be discussed here since we focus on the spectral formatting. The cavity is formed by 3 mirrors $\left(M_{1}, M_{2}\right.$ and $\left.M 3\right) . M_{2}$ and $M_{3}$ are high reflection mirrors at $589 \mathrm{~nm}$. The transmission of the output mirror $\mathrm{M}_{1}$ is $3 \%$. The amplifier medium is a Rhodamine 6G dye jet, diluted in ethylene glycol. Two selective elements reduce the spectral width: a Lyot filter with three quartz plates $(0.38 \mathrm{~mm}, 1.52$ $\mathrm{mm}$, and $6.08 \mathrm{~mm}$ ) positioned at the Brewster angle, and a Fabry Perot of free spectral range $225 \mathrm{GHz}$ (or $150 \mathrm{GHz}$ ) mm having a reflection coefficient of 32\%. The active element is an acousto-optic frequency shifter (AOS). The remarkable improvement over the last few years in the efficiency of acousto-optic modulators has enabled us to close the cavity on its first order. As we will see later, this leads to interesting dynamics. Our AOS is made of $\mathrm{TiO}_{2}$. Its Bragg geometry allows only first order, other orders being cancelled by destructive interference. This configuration gives a very high value of the efficiency $(97 \%)$ in first order at $589 \mathrm{~nm}$. The polarization of the intra cavity beam is 
rotated by $90^{\circ}$ after a single passage in the modulator, but remains preserved after one round trip.

The remarkable property of an acousto-optics modulator is to shift the optical frequency. Indeed, conditions of phase-matching (see Fig. 3) after one round trip, in first order, are such that the input frequency $v$ becomes $v+2 v_{a}$, where $v_{a}$ is the RF frequency applied to the modulator. The lowest frequency used, $40 \mathrm{MHz}$, is limited by technological considerations. As we shall see later, an even lower frequency would give better results, but the choice we made is a compromise for optimum acceptable losses. Physically, the frequency shift generates a laser line with no cavity mode. The shift prevents constructive and destructive interference, which is responsible for the mode structure. The temporal coherence of the laser line then is limited only by the selective elements introduced into the cavity. In the absence of selective elements the spectral band-width can be as large as the spectral band width of the dye $(\sim 100 \mathrm{~nm})$. This property could lead to interesting applications.

We analyzed the spectrum of various laser lines using an optical spectrum analyzer (Melles Griot) of high finesse ( 270 at $589 \mathrm{~nm}$ ) and a free spectral range of $7.5 \mathrm{GHz}$. Fig. 4 shows the result of three cases: i) single-longitudinal-mode laser, ii) multimode laser (the mirror $\mathrm{M}_{1}$ closes the cavity on the zeroth order of the modulator), iii) modeless laser. We clearly observe the random intensities of the multimode structure. This structure disappears when the cavity is closed in the AOS first order. A fitting procedure taking into account the overlap of successive modes of the spectrum analyzer gives a spectral line-width of $4.5 \mathrm{GHz}$. The experimental validation of the model, which will be described in paragraph 4, was made with a spectral width of $4.5 \mathrm{GHz}$. The model shows that by 
increasing the thickness of the intra cavity Fabry-Perot etalon down to a free spectral range of $150 \mathrm{GHz}$ (without changing its reflection coefficient) a line-width of $3 \mathrm{GHz}$ can be obtained, which is compatible with the width of the $\mathrm{D}_{2}$-line. This has been experimentally verified. Paragraph 5 will demonstrate the efficiency of both line-widths. Moreover, unlike single-longitudinal-mode lasers, our modeless laser is not very sensitive to temperature fluctuations. A room temperature control of about $0.3{ }^{\circ} \mathrm{C}$ is sufficient. The laser line remains on the $\mathrm{D}_{2}$-transition with no significant attenuation of the returned fluorescence flux. No electronic control of the spectral line is necessary. This all-optics modeless laser constitutes a huge simplification.

The dynamics of the modeless laser is very different from that of a single-longitudinalmode or multimode laser. The lasing threshold does not appear abruptly as in the case of normal lasers. Fig. 5 compares the experimental dependence of the output power on the pump power. In the case of a multimode laser (or single mode), the corresponding curve behaves as a first order transition with a rapid jump at the threshold. In the case of the modeless laser the transition is more progressive; the output power increases slowly over 6 decades while the pump power increases. The dynamics will be interpreted in the next paragraph. Adjustments and optimization of our modeless laser is very easy because the laser effect is almost always present. This property of the modeless laser confers on it a simplicity and reliability that are invaluable at an astronomical site.

\section{The model}

Dyes are amplifying media in which the rate-equation models can be applied, yielding

results with high degrees of accuracy ${ }^{32} 33$. Indeed, since the photon lifetime in the cavity $\left(\tau_{p} \sim 35 \mathrm{~ns}\right)$ is larger by an order of magnitude than that of the excited state $\left(\tau_{s} \sim 3.7 \mathrm{~ns}\right.$ for 
the R6G), the population inversion in the amplifier medium follows the intra-cavity flux adiabatically. No temporal shift exists between the intra-cavity field and the population inversion. To interpret our experimental results and to optimize the modeless laser we used a kinetical model ${ }^{30}$. The spectro-temporal evolution of the photon density $n(v, t)$, after a round trip, can be written

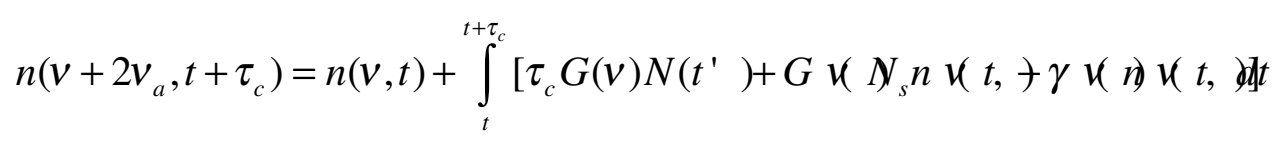

As we use a cw pump laser, we consider only the stationary case. The spectral distribution of the density of photons $n(v)$ is thus assumed to be time independent.

$$
n\left(v+2 v_{a}\right)-n(v)=2 v_{a} \frac{\partial n(v)}{\partial v}=\tau_{c}^{2} G(v) N_{s}+\tau_{c} G(v) N_{s} n(v)-\tau_{c} \gamma(v) n(v)
$$

After one cavity round trip, the optical frequency $v$ becomes $v+v_{a}$ and the density of photons increases by the spontaneous and the stimulated emission and decreases by the losses. We have:

$$
\begin{aligned}
& n(v) \quad=\text { density of photons at frequency } v \\
& N_{s} \quad=\text { number of dye molecules in the excited state } \\
& \tau_{c} \quad=\text { time of one round trip (s) } \\
& G(v) \quad=\text { gain by molecule }\left(\mathrm{s}^{-1}\right) \\
& \gamma(v) \quad=\text { intra cavity losses }\left(\mathrm{s}^{-1}\right) \\
& v_{a} \quad=\text { frequency of the progressive acoustic wave }(\mathrm{Hz})
\end{aligned}
$$

The population inversion $N_{s}$ in the stationary case is given by the ratio between pumping rate and emission rate of the excited state ${ }^{32}$ 


$$
N_{s}=\frac{\Gamma_{p}}{\left[\frac{1}{\tau_{s}}+\int G(v) n(v) d v\right]}
$$

Pumping rate is

$$
\Gamma_{p}=\eta P_{p} \frac{\lambda_{p}}{h c}
$$

where:

$P_{p} \quad=$ pump power

$\lambda_{p} \quad=$ wavelength of the pump laser

$\eta \quad$ = pumping efficiency

Pumping efficiency depends on many physical parameters (dye concentration, overlap of the pump beam and the spatial cavity mode, quality of the jet, reflections on the faces of the jet, triplet states ...). The loss rate is the sum of four terms: i) cavity losses, $\gamma_{c}$, including imperfections of the various optical elements, ii) useful losses, $\gamma_{\text {out }}$, of the output mirror, iii) transfer function of the Lyot filter, iv) transfer function of FP. One can write

$$
\begin{aligned}
& \gamma(v)=\gamma_{c}+\gamma_{\text {out }}+\gamma_{\text {Lyot }}(v)+\gamma_{F P}(v) \\
& \gamma_{c}=X . i s l_{c} \\
& \gamma_{\text {out }}=T . i s l_{c} \\
& \gamma_{L y o t}(v)=\frac{2}{\tau_{c}}\left(\frac{\pi v}{\Delta v_{L y o t}}\right)^{2} \\
& \gamma_{F P}(v)=\frac{2}{\tau_{c}} \ln \left[1+\frac{4 R}{\left(1-R^{2}\right)} \sin ^{2}\left(\pi \frac{v}{i s l_{F P}}\right)\right]
\end{aligned}
$$

with

$X, T, R=$ cavity losses, transmission of the output mirror and reflection coefficient of the FP (assumed to be constant in the spectral band of the laser) (\%) 
$\Delta v_{L y o t}=$ free spectral range Lyot filter $(\mathrm{Hz})$

$i s l_{c}, i s l_{F P}=$ free spectral range of the cavity $\left(1 / \tau_{\mathrm{c}}\right)$ and free spectral range of the $\mathrm{FP}(\mathrm{Hz})$ Equations (14) and (15) were solved numerically with the parameter values corresponding to experimental conditions of Tab. 1.

The photon density $n(v)$ is calculated for a given pump power $P_{p}$. The output power of the modeless laser is then calculated from the following expression

$$
P_{\text {out }}=\gamma_{\text {out }} h v_{\text {out }} \int n(v) d v
$$

Fig. 5 shows excellent agreement with experiment over 6 decades. Only three parameters were fitted (Tab. 1). Cavity losses $X$ as well as pumping efficiency $\eta$ can be improved by optimizing the optical elements of the cavity. The low value of $\eta$ is due essentially to a pump mirror that was designed for argon laser pumping and which was not optimized for the VERDI YAG laser (coating and radius of curvature). The value of the gain $G$ is in

good agreement with values found in the literature ${ }^{33}$. A comfortable output power and high stability are obtained. For ELP-OA it is clear that a cw YAG laser of $4 \mathrm{~W}$ could easily pump two modeless lasers. As far as the spectral line-width is concerned, Fig. 6 also shows good agreement with numerical calculations.

\section{Modeless laser excitation of the $\mathbf{D}_{2}$-line and discussion}

To measure the efficiency of our modeless laser compared to a single-longitudinal-mode laser, we set-up a photometry experiment using a home-made sodium oven (Fig. 7). The modeless laser beam (or a single-mode laser Coherent 599-21) is focused by a lens of focal length $f=200 \mathrm{~mm}$ in a sodium cell. In both cases, the waist $w$ is maintained at a value close to $100.5 \mu \mathrm{m}$. This value gives a power density $P_{w}$ that is compatible with the ELPOA project. The sodium cell is made of silica with molecularly welded windows of high 
quality $(\lambda / 8)$ and is filled with pure sodium. This cell is placed in an oven at $130{ }^{\circ} \mathrm{C}$, stabilized within $0.01{ }^{\circ} \mathrm{C}$. The fluorescence of the $\mathrm{D}_{2}$-line is collected by a silica optical fiber of numerical aperture 0.22 . The input fiber-end is located at $20 \mathrm{~mm}$ perpendicularly to the laser beam. At the other fiber-end, the fluorescence flux is measured with a PMT in front of which a $2 \mathrm{~nm}$ interference filter is centered on the $\mathrm{D}_{2}$-line. The detection system was calibrated to provide absolute measurements. In this paper, however, we are interested in relative measurements only. The aim is to compare both types of lasers under the same conditions. A Shack-Hartmann wave front sensor (HASO32 Imagine Optic) characterizes the beam wave front, which was maintained identical for both lasers. With a $100.5 \mu \mathrm{m}$ waist, the Rayleigh length $Z_{R}$ is $53 \mathrm{~mm}$. Taking into account the above geometry, the diameter of the laser beam can, to a good approximation be taken as constant inside the observation zone of the fluorescence. The output beam after the sodium cell is sent to the spectrum analyzer (isl $=7.5 \mathrm{GHz}$, finesse $>250$ ) described above in order to measure the spectral width of the laser beam. Part of the beam is sent to a monochromator calibrated with a sodium hollow cathode. Finally a wheel with 15 calibrated metallic neutral-density filters of high quality (Melles Griot) is placed directly in front of the cell. The mean power $P_{m}$ of the laser is measured with a power meter (Ophir) placed before the attenuators, where it remained throughout all the experiments.

Three cases were studied (see Fig. 8): i) single-longitudinal-mode laser of $1 \mathrm{MHz}$ linewidth, centered on the maximum of the hyperfine transition $F=2$ (see Fig. 8), ii) modeless laser of $4.5 \mathrm{GHz}$ line-width and iii) modeless laser of $3 \mathrm{GHz}$ line width. As the $\mathrm{M}^{2}$ laser beam parameter is close to 1 (typically 1.05 ), we define the spatial power density by $P_{w}=\frac{T_{f} P_{m}}{\pi w^{2}}$, where $T_{f}$ is the transmission of the neutral filter used. Fig. 9 shows the 
variation of the fluorescence of the $\mathrm{D}_{2}$-transition with $P_{w}$. To extract the gain introduced by our modeless laser, the experimental curves were fitted to a double exponential. Under the current conditions, Fig. 9 shows that the gain of the modeless laser compared to the single mode laser can reach a factor of 6 , a gain that is close to the theoretical value (see Fig. 1). A further optimization might consist in filtering the line of the modeless laser with a filter to match the exact shape of the spectral $\mathrm{D}_{2}$-line. A Faraday filter could be

considered $^{34}{ }^{35} \cdot$ Keck $^{1}$ and ELP-OA ${ }^{16}$ project specifications are noted on Fig. 9 by arrows. For ELP-OA project and in the current state of the art, we expected to gain at least a factor of 5 for the $\mathrm{D}_{2}$-star.

\section{Conclusion}

The modeless laser has remarkable properties. Its description by the simplified model that we use gives a satisfactory interpretation of some aspects of its slow dynamics. It does not, however, provide a detailed description of the corresponding electric field. Further modeling studies are needed to get a more detailed description

Saturation of the sodium atom excited by pulsed lasers ceases to be a problem if one uses a high repetition rate pulsed modeless laser, up to average powers in excess of $100 \mathrm{~W}$. The modeless laser that we have developed would offer a gain of almost 2 magnitudes for a monochromatic artificial $\mathrm{D}_{2}$-star. It could give a gain of 1.4 magnitudes (see Fig. 9) for the laser system recently installed at the Keck observatory. Within the framework of the polychromatic project ELP-OA, a gain of between 2.5 and 4 magnitudes can be expected for the $\mathrm{D}_{1}$ and UV (330 nm) stars, which will be used to correct the tip-tilt. This result makes this project much more credible. 
Moreover, the laser can be used with great ease. Its simplicity allows the design of a compact and reliable laser system. We are developing an intra-cavity preamplifier that will greatly simplify the usual set-up: only one traditional amplifier will then be required to obtain the $25 \mathrm{~W}$ necessary for ELP-OA but also for the monochromatic laser guided star projects.

\section{Acknowledgments}

We are indebted to the CNRS-MRCT which has partly funded this work. We thank JeanLouis Cheval for the special care and attention given in the technical part of this work. We gratefully acknowledge helpful reading of the manuscript with Erik Geissler. 


\section{Table caption}

Tab. 1. Values of parameters used in the numerical calculations. Fitted parameters are indicated in the last column. 


\begin{tabular}{|l|l|l|}
\hline Parameter & Value & Fitted \\
\hline$v_{a}$ & $40 \mathrm{MHz}$ & No \\
\hline$\lambda_{p}$ & $532 \mathrm{~nm}$ & No \\
\hline$\lambda_{\text {out }}$ & $589 \mathrm{~nm}$ & No \\
\hline$\tau_{p}$ & $35 \mathrm{~ns}$ & No \\
\hline$\tau_{s}$ & $3.7 \mathrm{~ns}$ & No \\
\hline$T$ & $4 \%$ & No \\
\hline$R$ & $32 \%$ & No \\
\hline$\Delta v_{L y o t}$ & $1800 \mathrm{GHz}$ & No \\
\hline$i s l_{c}$ & $283 \mathrm{MHz}$ & No \\
\hline$i s l_{F P}$ & $225 \mathrm{GHz}$ & No \\
\hline$X$ & $10 \%$ & Yes \\
\hline$\eta$ & $32 \%$ & Yes \\
\hline$G$ & $11.10^{-3} \mathrm{~s}^{-1}$ & Yes \\
\hline
\end{tabular}

Table 1 


\section{Figure captions}

Fig. 1.

Return fluorescence flux versus average laser power, for three types of laser: $1 \mathrm{MHz}$ single-mode laser (doted lines), $3 \mathrm{GHz}$ and 4.5 GHz modeless laser (dashed and solid lines respectively). The lines with and without crosses correspond respectively to: i) $80 \mathrm{~ns}$ pulse width, $30 \mathrm{kHz}$ repetition rate and ii) $40 \mathrm{~ns}$ pulse width, $15 \mathrm{kHz}$ repetition rate. The star corresponds to Morris's calculations (see text). The right-hand y-scale is a normalized scale with the calculated point of the $1 \mathrm{MHz}$ single-longitudinalmode case at $25 \mathrm{~W}$ power. It shows the gain for different solutions.

Fig. 2.

Modeless laser configuration. Two dye jets are pumped by a cw YAG laser and a QSwitched YAG laser respectively. The mirrors M2-M3 are highly reflecting for R6G dye. M1 has $3 \%$ transmission coating at $589 \mathrm{~nm}$. The acousto-optic shifter (AOS) is made of TiO2. A Lyot filter and an etalon (FP) control the line-width and the absolute wavelength.

Fig. 3.

Round trip phase matching conditions of the AOS. $\mathbf{k}_{i}, \mathbf{k}_{i}^{\prime}$ and $\mathbf{k}_{d}, \mathbf{k}_{d}^{\prime}$ are the incident and diffracted wave vectors of the first and return passage respectively. $k_{a}$ is the acoustic wave vector. After a round trip, the optical frequency of the first order diffracted wave increases by two acoustic quanta $v_{a}$.

Fig. 4. 
Laser line spectrum analyzed with a high resolution ( 25 MHz) spectral analyzer. a) single-mode laser Coherent 599-21, b) multimode laser (same configuration as in Fig. 2 but with the RF power off and the output mirror $M_{1}$ closing the cavity on the first order of the AOS, c) modeless laser.

Fig. 5.

Logarithm of the output power of the multimode and modeless lasers versus the dye pump power. The spontaneous emission signal, within the spatial cavity mode, is about $10^{-5} \mathrm{~mW}$. Over six decades, the multimode laser shows a first order transition whereas the modeless laser shows a second order transition.

Fig. 6.

Experimental and calculated spectral line width of the modeless laser versus the dye pump power.

Fig. 7.

Set up of the $D_{2}$-fluorescence photometry experiment. The modeless laser and the single-longitudinal-mode laser (Coherent 599-21) have a similar cavity, which allows a fine control of the same beam profile in front of the optical fiber that collects the sodium fluorescence. The beam profile is monitored by a Shack-Hartmann wave front sensor (HASO32, Imagine Optic). A high resolution spectrum analyzer (FP 7.5 GHz) records the laser spectrum. The same set of neutral filters is used for both experiments.

Fig. 8. 
Sodium Doppler-hyperfine spectrum. The two maxima correspond to the ground state $3 \mathrm{~S}_{1 / 2}$ hyperfine structure. The three laser lines studied are represented: $1 \mathrm{MHz}$ single-mode, $3 \mathrm{GHz}$ modeless and $4.5 \mathrm{GHz}$ modeless.

Fig. 9.

Experimental comparison of the $\mathrm{D}_{2}$-line fluorescence intensity for three laser lines studied versus the power density. The PMT detector and electronic parameters are maintained identical for the three studied cases. For the ELP-OA project, by comparison with single-mode laser, the gain of the $3 \mathrm{GHz}$ modeless laser is better than 5. 


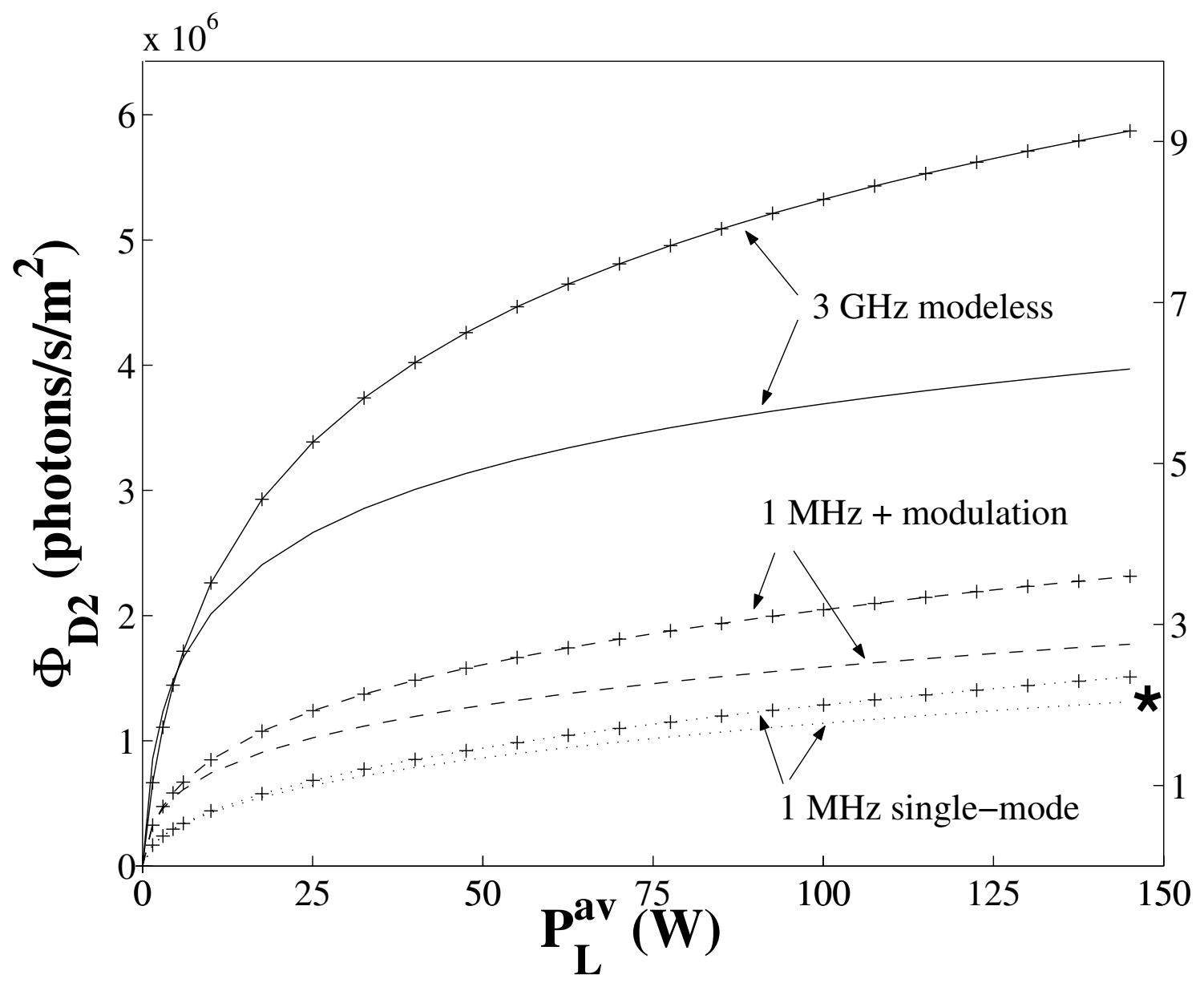

Figure 1 


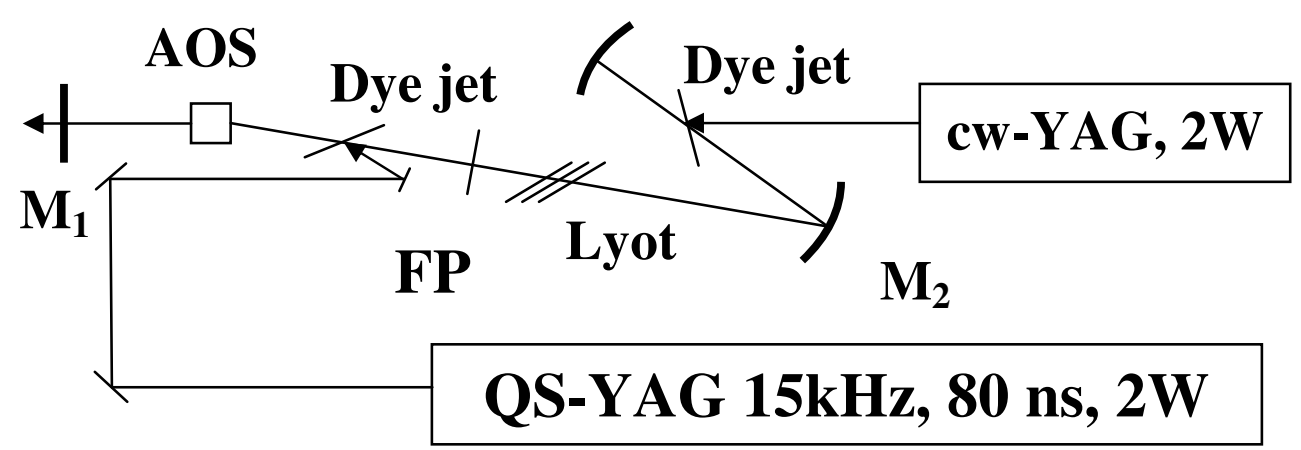

Figure 2 


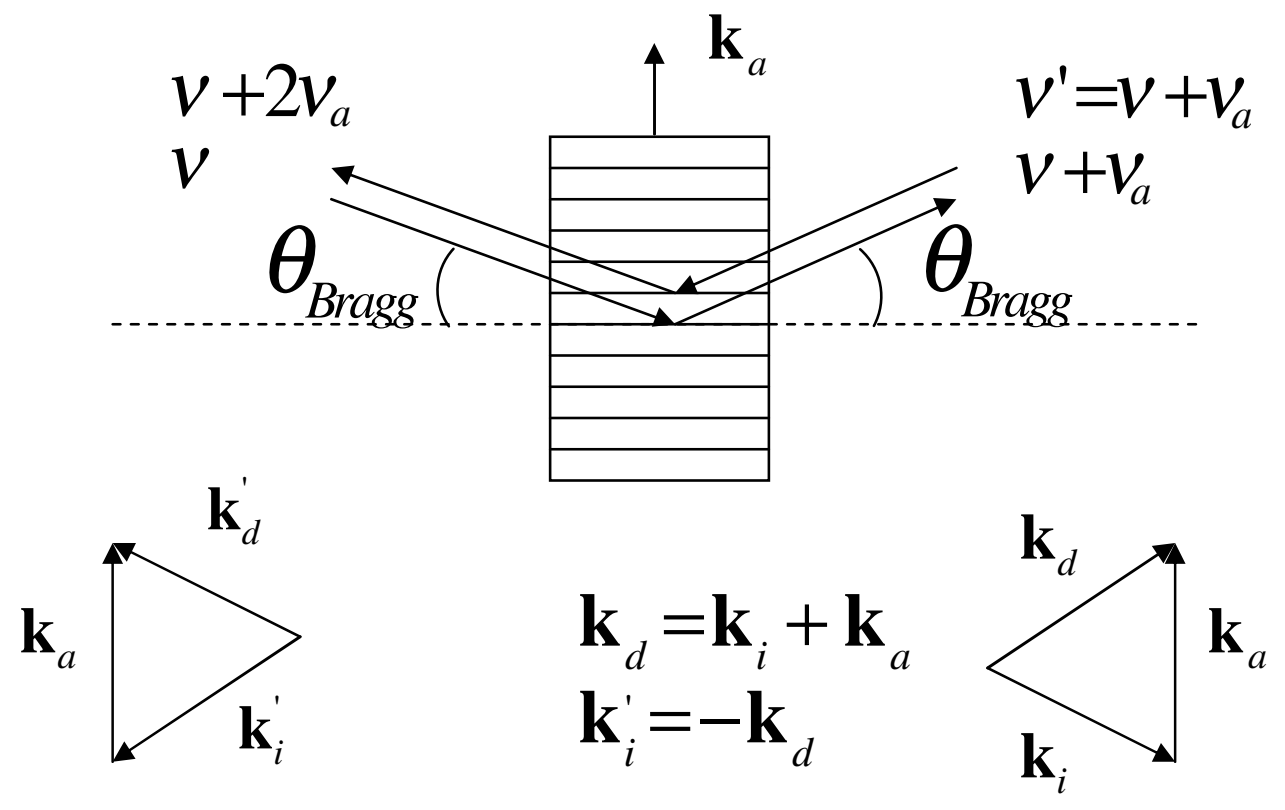

Figure 3 


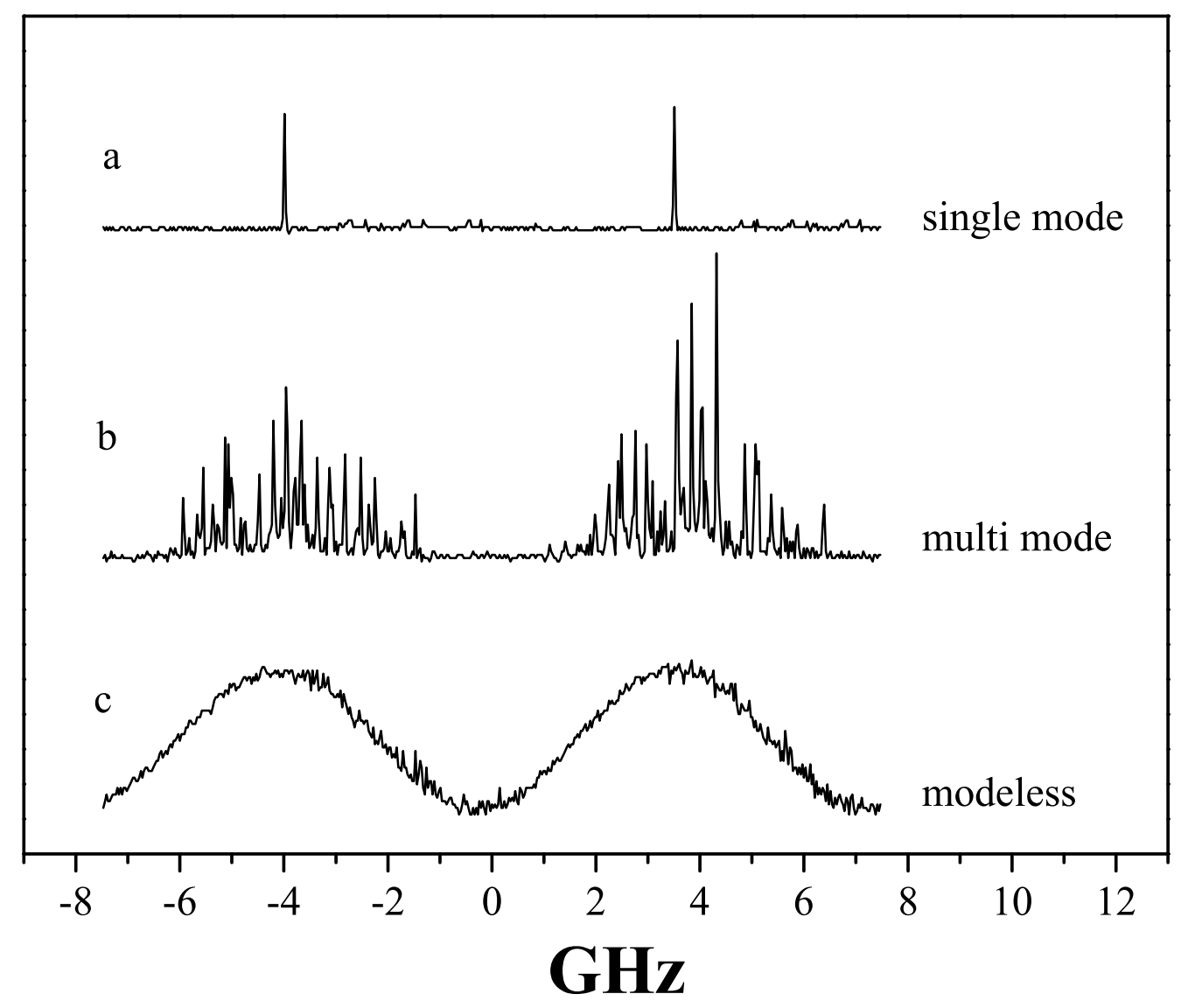

Figure 4 


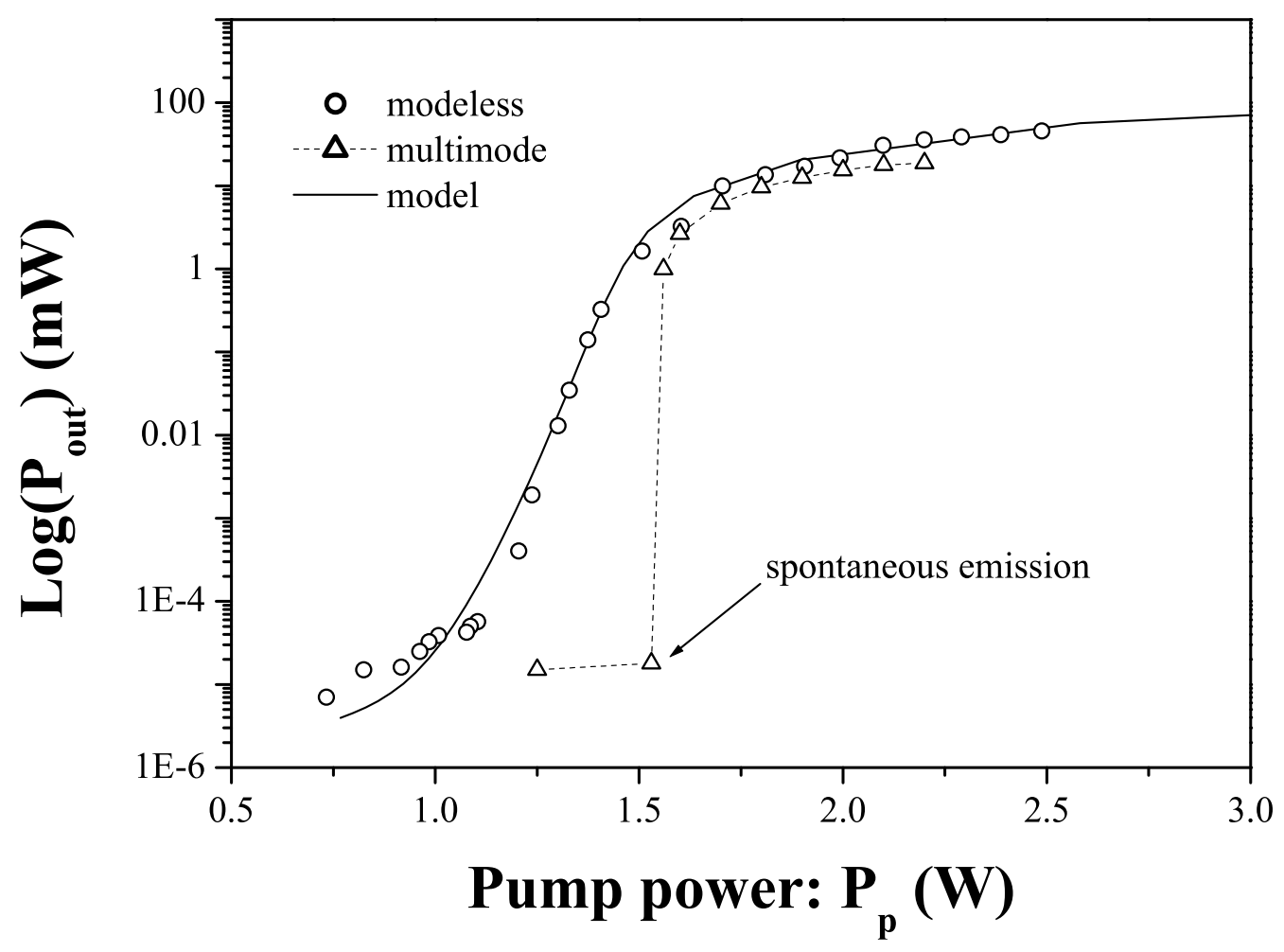

Figure 5 


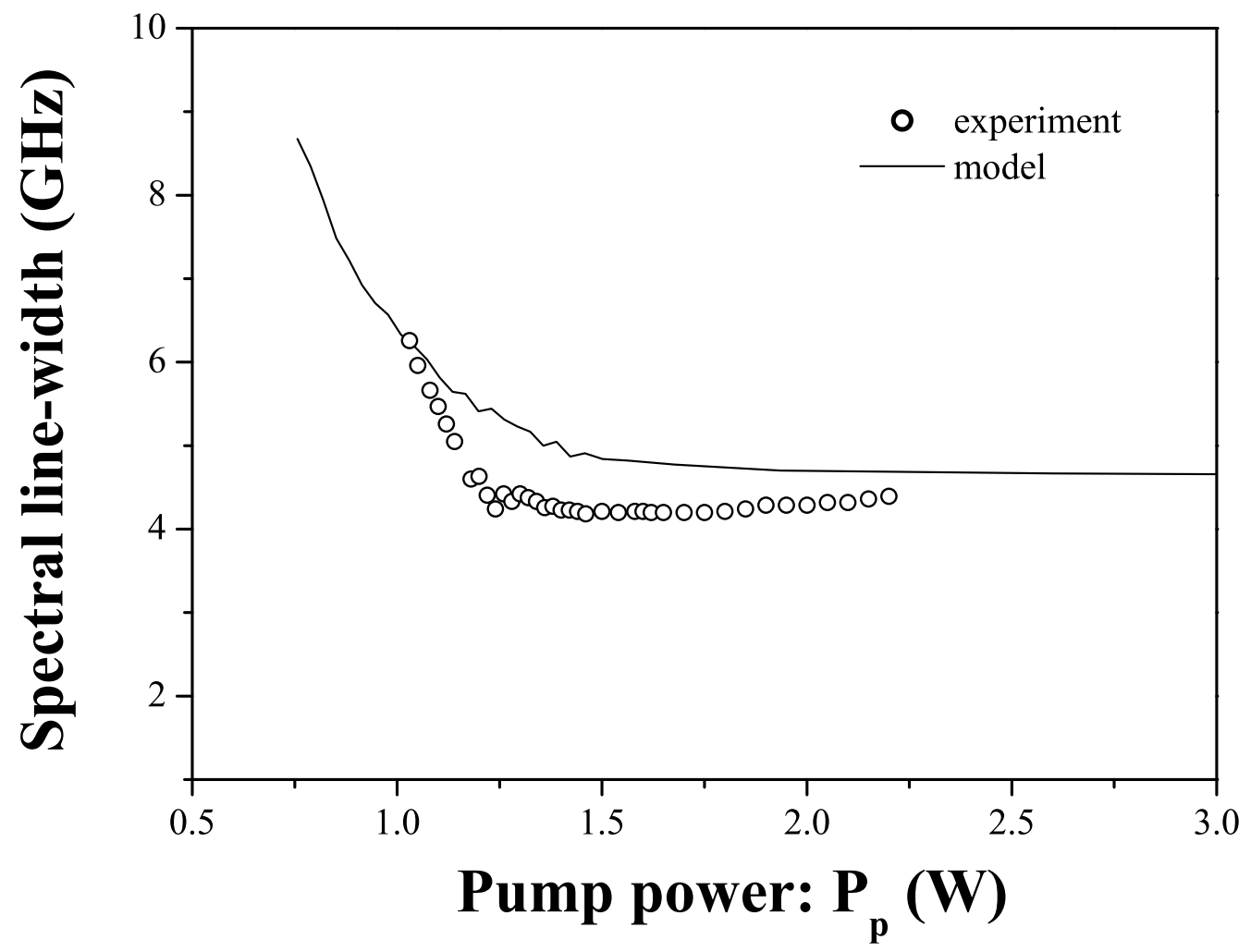

Figure 6 


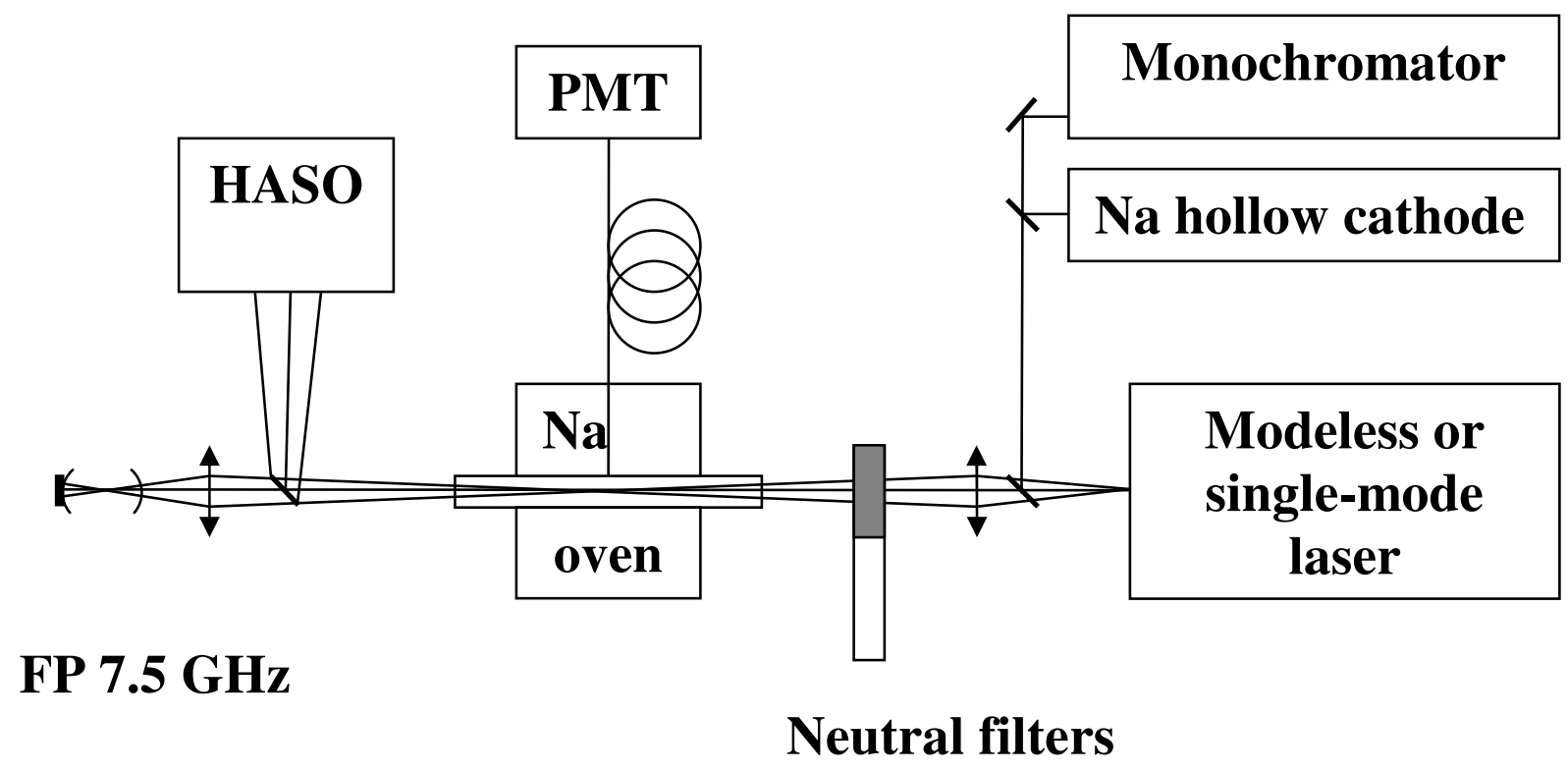

Figure 7 


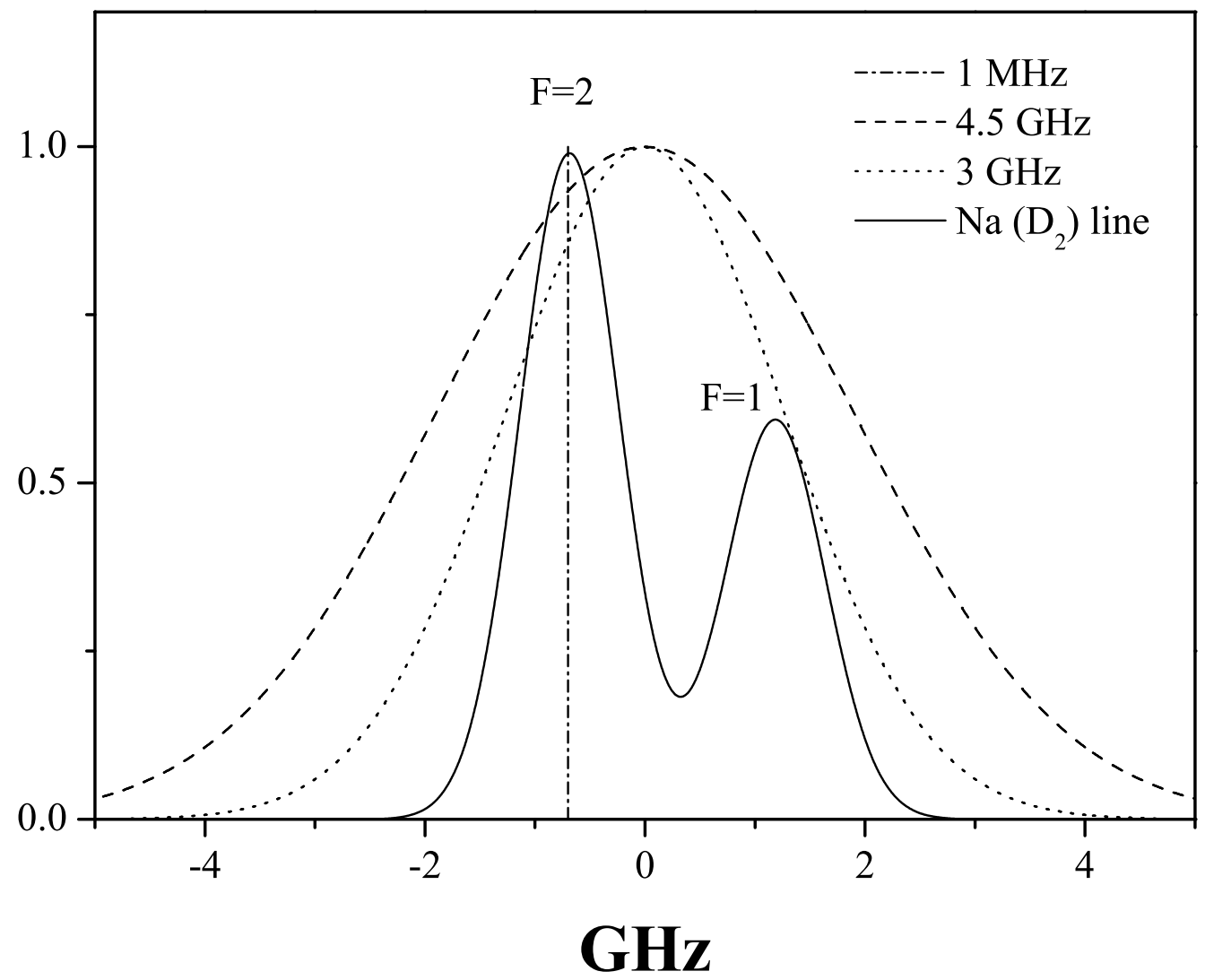

Figure 8 


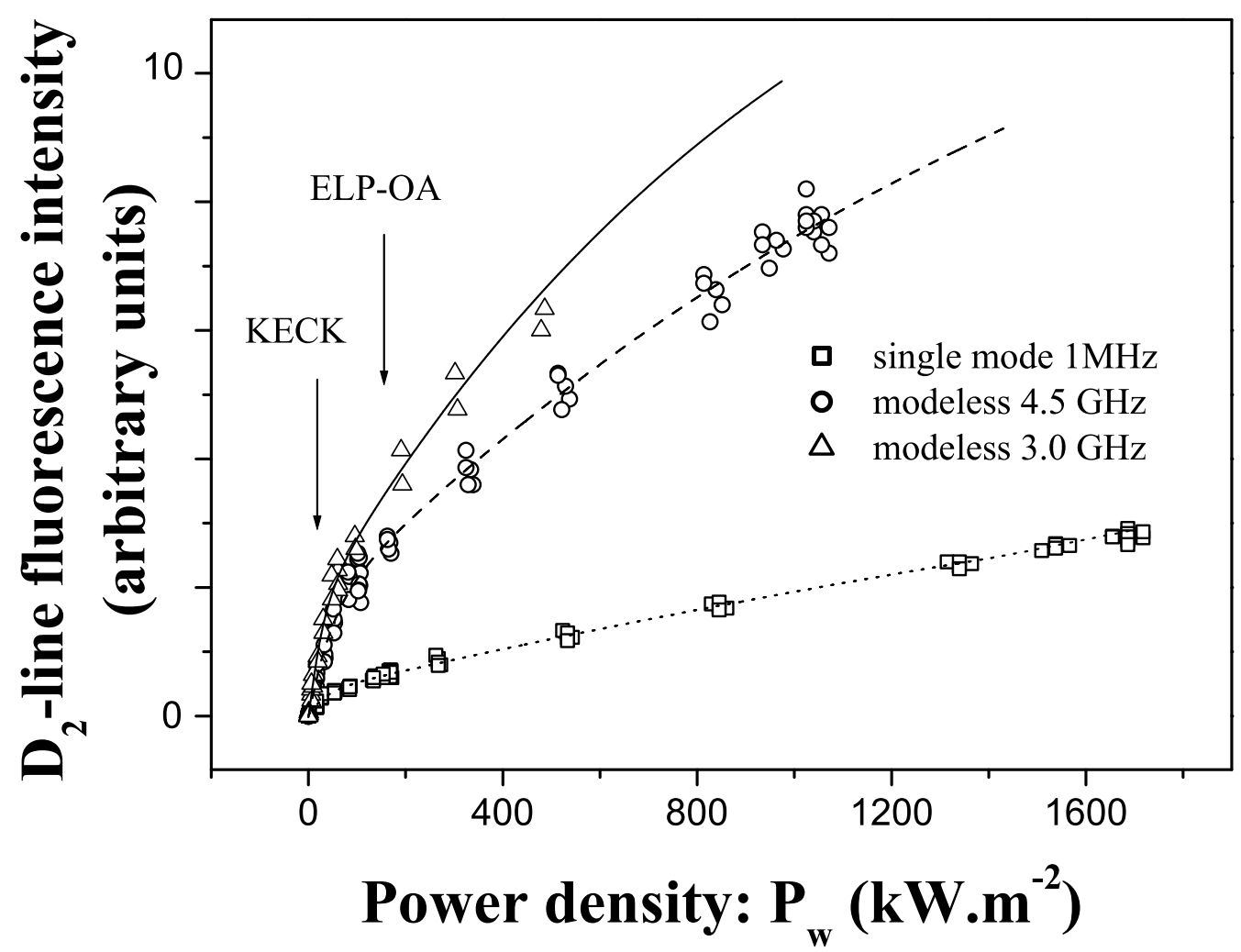

Figure 9 


\section{References}

${ }^{1}$ D. M. Pennington, "Laser Technologies for Laser Guided Adaptive Optics“, NATO Summer Institute on Optics for Astrophysics, Corsica, France, (2002).

${ }^{2}$ L.A. Thompson and C.S. Gardner, "Experiments on laser guide stars at Mauna Kea Observatory for adaptive imaging in astronomy “, Nature 328, 229-231 (1987).

${ }^{3}$ K. Avicola, J.M. Brase, R.J. Morris, H. Bissinger, J.M. Duff, H.W. Friedman, D.T. Gavel, C.E. Max, S.S. Olivier, R. Presta, D.A. Rapp, J.T. Salmon, and K. Valtjen, "Sodium-layer laser-guide-star experimental results", J. Opt. Soc. Am. A 11, 825-831 (1994).

${ }^{4}$ M. Llyod-Hart, J.R. Angel, D.G. Sandler, T.D. Goesberck, T. Martinez, and B.P. Jacobsen, “Design of the $6.5 \mathrm{~m}$ MMT adaptative optics system and results from its prototype system FASTTRAC II", in Optical Telescopes of Today and Tomorrow, Arne L. Ardeberg, ed., Proc. SPIE. 2871, 880-889 (1997).

5 A. Quirrenbach, W. Hackenberg, H.C. Holstenberg, and N. Wilnhammer, "Sodium laser guide star system of ALFA", in Adaptive Optics and Applications, Robert K. Tyson and Robert Q. Fugate, eds., Proc. SPIE 3126, 35-43 (1997).

${ }^{6}$ S.S. Olivier, C.E. Max, J. An, K. Avicola, H.D. Bissinger, J.M. Brase, H.W. Friedman, D.T. Gavel, B. Macintosh, and K.E. Waltjen , "First significant image improvement from the Lick Observatory laser guide star adaptative optics system”, Am. Astro. Soc. 28, 1324-1328 (1996). 
${ }^{7}$ E.J. Kibblewhite, R. Vuilleumier, B. Carter, W.J. Wild, and T.H. Jeys, 'Implementation of a cw -and pulsed-laser beacons for astronomical adaptive optics systems", in Adaptive Optics in Astronomy, Mark A. Ealey, Fritz Merkle, eds, Proc. SPIE. 2201, 272-283 (1994).

${ }^{8}$ P. Wizinowich, D.S. Acton, C. Shelton, P. Stromski, J. Gathright, K. Ho, W. Lupton, K. Tsubota, O. Lai, C. Max, J. Brase, J. An, K. Avicola, S. Olivier, D. Gavel, B. Macintosh, A. Ghez, and J. Larkin, "First Light Adaptive Optics Images from the Keck II Telescope: A New Era of High Angular Resolution Imagery”, P ub. Astro. Soc. Pac. 112, 315-319 (2000).

9 D. Bonaccini, W. Hackenberg, M.J. Cullum, E. Brunetto, T. Ott, M. Quattri, E. Allaert, M. Dimmler, M. Tarenghi, A. Van Kersteren, C. Di Chirico, B. Buzzoni, P. Gray, R. Tamai, and M. Tapia, 'ESO VLT laser g uide star facility", in Adaptive Optics Systems and Technology II, Robert K. Tyson, Domenico Bonaccini, Michael C. Roggemann, eds., Proc SPIE 4494, 276-289 (2002).

${ }^{10}$ C. D' Orgevill,eB.J. Bauman, J.W. Catone, B.L. Ellerbroek, D.T. Gavel, and R.A. Buchroeder, A. Richard, 'Gemini north and south laser guide star systems requirements and preliminary designs", in Adaptive Optics Systems and Technology II, Robert K. Tyson, Domenico Bonaccini, Michael C. Roggemann, eds., Proc. SPIE 4494, 302-316 (2002).

11 J.M. Telle, P.W. Milonni, and R.Q. Fugate, “Update on 589 -nm sodium star pump laser requirements", in Adaptive Optical Systems Technology, Peter L. Wizinowich, ed., Proc. SPIE 4007, 252-257 (2000). 
${ }^{12}$ D.N. Payne, Patent \#IL-10737,( 2002).

13 W. Hackenberg and D. Bonaccini, "Fiber Raman laser development for multiconjugate adaptive optics with sodium laser guide stars", in Adaptive Optics Systems and Technology II, Robert K. Tyson, Domenico Bonaccini, Michael C. Roggemann, eds. Proc. SPIE. 4494, 271-275 (2002).

14 R. Foy, A. Migus, A. Biraben, G. Grynberg, P. R. McCullough, and M. Tallon, 'The polychromatic artificial sodium star: a new concept for correcting the atmospheric tilt", Astron. Astrophys. Suppl. Ser. 111, 569-578 (1995).

15 R. Foy, J.P. Pique, A. Petit, P. Chevrou, V. Michau, G. Grynberg, A. Migus, N. Georges, V. Bellanger, F. Biraben, R. Deron, H. Feys, F.C. Foy, C. Hoegemann, M. Laubscher, D. Müller, C. d' Orgevill,eO. Peillet, M. Redfern, M. Schoeck, P. Segonds, R. Soden, M. Tallon, E. Thiebaut, A.A. Tokovinin, A. Andrei, J. Vaillant, and J.M. Weulerse, 'ELP-OA: toward the tilt measurement from a polychromatic laser guide star', in Adaptive Optical Systems Technology, Peter L. Wizinowich, ed. Proc. SPIE 4007, 284-295 (2000).

16 M. Schöck, R. Foy, M. Tallon, L. Noethe, and J.P. Pique, 'Performance analysis of polychromatic laser guide stars used for wavefront tilt sensing", Mon. Not. R. Astron. Soc. 337, 910-920 (2002).

17 G. Megie, F. E. Blamont, and M. L. Chanin, "Simultaneous nighttime lidar measurements of atmospheric sodium and potassium", Planet. Space Sci. 26, 27-35 (1977). 
18 B. M. Welsh and C. S. Gardner, "Nonlinear resonant absorption effects on the design of resonance fluorescence lidars and laser guide stars”, Appl. Opt. 28, 4141-4153 (1989). ${ }^{19}$ K. Avicola, J.M. Brase, R.J. Morris, H. Bissinger, J.M. Duff, H.W. Friedman, D.T. Gavel, C.E. Max, S.S. Olivier, R. Presta, D.A. Rapp, J.T. Salmon, and K. Valtjen, “Sodium-layer laser-guide-star experimental results", J. Opt. Soc. Am. A, 11, 825-831 (1994).

20 J. R. Morris, "Efficient excitation of a mesospheric sodium laser guide star by intermediate-duration pulses", J. Opt. Soc. Am. A 11, 832-845 (1994).

${ }^{21}$ M. Schoeck, R. Foy, J.P. Pique, P. Chevrou, N. Georges, A. Petit, V. Bellanger, H. Fews, F.C. Foy, C. Hoegemann, M. Laubscher, O. Peillet, P. Segonds, M. Tallon, and J.M. Weulersse, 'PASS -2: quantitative photometric measurements of the polychromatic laser guide star", in Adaptive Optical Systems Technology, Peter L. Wizinowich, ed., Proc. SPIE 4007, 296-307 (2000).

${ }^{22}$ M. Schoeck, R. Foy, J.P. Pique, M. Tallon, P. Segonds, M. Laubscher and O. Peillet, 'PASS -2: photometry of the polychromatic laser guide star', in Adaptive Optics Systems and Technology, Robert K. Tyson, Robert Q. Fugate, eds., Proc. SPIE 3762, 321-329 (1999).

${ }^{23}$ H.W. Friedman, Lawrence Livermore National Laboratory, CA, USA, private communication (2000).

${ }^{24}$ G. Froc, E. Rosencher, B. Attal-Trétout, and V. Michau, 'Photon return analysis of a polychromatic laser guide star", Opt. Comm. 178, 405-409 (2000). 
${ }^{25}$ V. Bellanger, 'Etude de l'interaction laser sodium dans le cadre du projet de l'étoile laser polychromatique pour l'optique adaptative", Thesis of the Université Pierre et Marie Curie, Paris VI, 16 ${ }^{\text {th }}$ January, 2002.

${ }^{26}$ L. Michaille, J.C. Dainty, J. Quartel, N.J. Wooder, and T. Gregory, 'Progress report on the sodium laser monitoring laser guide star adaptive optics", New Astro. Rev. 45, 69-72 (2001).

${ }^{27}$ J.P. Pique, Lab. Spectrométrie Physique, Université Joseph Fourier, UMR 5588

CNRS- Grenoble I, B.P. 87, 38402 Saint Martin d' Hèresprivate communication (2003).

28 P. Edwart, “A modeless, variable bandwidth, tunable laser”, Opt. Comm. 55, 124-126 (1985).

29 I. C.M. Littler, S. Balle, and K. Bergmann, “The cw mode less laser: spectral control, performance data and build-up dynamics", Opt. Comm. 88, 514-522 (1992).

${ }^{30}$ I. C.M. Littler and J. H. Eschner, "The cw modeless laser: model calculations of an active frequency shifted feedback cavity”, O pt. Comm. 87, 44-52 (1992).

31 J. Liang, L. Moi, and C. Fabre, “The 'lamp-laser' : realization of a very long cavity dye laser", Opt. Comm. 52, 131-135 (1984).

32 O. Svelto, in Principles of lasers, 4th edition, edited by D.C. Hanna (Plenum, New York and London, 1998), Vol. 1, Chap. 7, p.258.

33 F.J. Duarte and L.W. Hillman, in Dye Laser Principles, edited by P.F. Liao (Academic Press, San Diego, 1990), Vol. 1, Chap. 5, p.194.

${ }^{34}$ H. Chen, C. Y. She, P. Searcy, and E. Korevaar, "Sodium-vapor dispersive Faraday filter”, Opt. Lett. 18, 1019-1021 (1993). 
35 Z. Hu, X. Sun, Y. Liu, L. Fu, and X. Zeng, “Temperature properties of Na dispersive

Faraday optical filter at $\mathrm{D}_{1}$ and $\mathrm{D}_{2}$ line", Opt. Comm. 156, 289-293 (1998). 